\title{
Effects of steroids and angiotensin converting enzyme inhibition on circumferential strain in boys with Duchenne muscular dystrophy: a cross-sectional and longitudinal study utilizing cardiovascular magnetic resonance
}

\author{
Kan N Hor ${ }^{1 *}$, Wojciech Mazur ${ }^{2}$, Michael D Taylor ${ }^{1}$, Hussein R Al-Khalidi ${ }^{3}$, Linda H Cripe ${ }^{1}$, John L Jefferies ${ }^{1}$, \\ Subha V Raman ${ }^{4}$, Eugene S Chung ${ }^{2}$, Kathi J Kinnett', Katelyn Williams', William M Gottliebson ${ }^{1}$ and \\ D Woodrow Benson'
}

\begin{abstract}
Background: Steroid use has prolonged ambulation in Duchenne muscular dystrophy (DMD) and combined with advances in respiratory care overall management has improved such that cardiac manifestations have become the major cause of death. Unfortunately, there is no consensus for DMD-associated cardiac disease management. Our purpose was to assess effects of steroid use alone or in combination with angiotensin converting enzyme inhibitors (ACEI) or angiotension receptor blocker (ARB) on cardiovascular magnetic resonance (CMR) derived circumferential strain $\left(\varepsilon_{c C}\right)$.

Methods: We used CMR to assess effects of corticosteroids alone (Group A) or in combination with ACEI or ARB (Group B) on heart rate (HR), left ventricular ejection fraction (LVEF), mass (LVM), end diastolic volume (LVEDV) and circumferential strain $\left(\varepsilon_{c c}\right)$ in a cohort of 171 DMD patients $>5$ years of age. Treatment decisions were made independently by physicians at both our institution and referral centers and not based on CMR results.

Results: Patients in Group A (114 studies) were younger than those in Group B (92 studies)(10 \pm 2.4 vs. $12.4 \pm 3.2$ years, $p<0.0001)$, but HR, LVEF, LVEDV and LVM were not different. Although $\varepsilon_{\mathrm{cc}}$ magnitude was lower in Group $B$ than Group A (-13.8 \pm 1.9 vs. $-12.8 \pm 2.0, p=0.0004)$, age correction using covariance analysis eliminated this effect. In a subset of patients who underwent serial CMR exams with an inter-study time of $\sim 15$ months, $\varepsilon_{c c}$ worsened regardless of treatment group.
\end{abstract}

Conclusions: These results support the need for prospective clinical trials to identify more effective treatment regimens for DMD associated cardiac disease.

\section{Background}

Duchenne muscular dystrophy (DMD) is an X-linked recessive disorder affecting approximately 1:3,500 males [1-3]. Boys with DMD are currently treated with corticosteroids at a young age to prolong ambulation. This therapy combined with improvements in respiratory care

\footnotetext{
* Correspondence: kan.hor@cchmc.org

'The Heart Institute, Cincinnati Children's Hospital Medical Center, Cincinnati, Ohio, USA

Full list of author information is available at the end of the article
}

have resulted in increased survival [4-6] such that DMDassociated heart disease is now the leading cause of mortality [7-11]. Myocardial changes, as a result of the lack of dystrophin, consist of cell membrane degradation, interstitial inflammation, edema, fatty replacement and fibrosis [12-15]. Despite reports in small cohorts of the beneficial cardiovascular effects of corticosteroids $[6,16]$ and angiotensin converting enzyme inhibitors (ACEI)/ angiotensin receptor blockers (ARB) [17-19], there is no consensus regarding the management of DMD-associated
C Biomed Central

() 2011 Hor et al; licensee BioMed Central Ltd. This is an Open Access article distributed under the terms of the Creative Commons Attribution License (http://creativecommons.org/licenses/by/2.0), which permits unrestricted use, distribution, and reproduction in any medium, provided the original work is properly cited. 
cardiac disease. In the absence of conclusive randomized clinical trial data, steroids, ACEI, ARB, beta blockers (BB) and/or digoxin have been used empirically [20,21]; beneficial effects of positive inotropic agents have been reported in boys with depressed left ventricular function and advanced cardiac disease [22].

Defining clinical endpoints for cardiac therapy in DMD boys is challenging. Recent studies from our center and others have shown that indices of global left ventricular (LV) function, e.g. mass, volume and ejection fraction (EF) are not adequate to detect cardiac dysfunction in young DMD patients [23-25], but myocardial strain $(\varepsilon)$, an indicator of local myocardial deformation normalized to its original dimension, can detect occult cardiac disease early in the course of DMD despite normal EF. Further, depressed $\varepsilon_{\mathrm{cc}}$ magnitude correlates with disease progression $[24,25]$.

The purpose of this study was to retrospectively compare cardiac effects of corticosteroid monotherapy versus corticosteroids plus ACEI or ARB in a cohort of DMD patients followed at our center. We compared effects on both global LV function (EF) and local LV function $\left(\boldsymbol{\varepsilon}_{\mathrm{cc}}\right)$ determined by cardiovascular magnetic resonance (CMR).

\section{Methods}

DMD patients $>5$ years of age who underwent CMR from February 2006 to February 2010 were identified from the CMR database at Cincinnati Children's Hospital Medical Center (CCHMC). The diagnosis of DMD was confirmed by physical examination and identification of a dystrophin mutation. This study was approved by the Institutional Review Board.

Patients were identified for inclusion in one of two treatment groups. Group A was only treated with corticosteroids (either deflazacort or prednisone). Group B was being treated with corticosteroids plus ACEI (lisinopril or enalapril) or ARB (losartan). All patients in Group B had been treated with ACEI/ARB for a minimum of 12 months prior to CMR, and all patients in both groups had been treated with corticosteroids for at least 12 months prior to CMR. Initiation of corticosteroids and ACEI/ARB was determined exclusively by treating physician preference and were not based on CMR results. DMD boys not treated with corticosteroids or treated with beta blockers were excluded.

CMR studies were conducted on either a 3 Tesla (Trio, Siemens Medical Solutions, Erlangen, Germany) or 1.5 Tesla (Signa Excite, General Electric Healthcare, Milwaukee, WI) scanner based on clinical availability, independent of the patient's clinical status or prior type or field strength of the first study. Cardiac functional imaging was performed using retrospective ECG-gating, segmented Steady State Free Precession (SSFP) technique after localized shimming and/or frequency adjusting. Subjects were breath-held as tolerated; for those subjects who could not adequately breath-hold, a free breathing technique with multiple signal averaging was used. Standard imaging included a short axis stack of cine SSFP images from cardiac base to apex; the short axis was prescribed as the perpendicular plane to the left ventricular long axis in 2 and 4 chamber views as previously described $[26,27]$. Typical scan parameters included FOV $=32-38$ $\mathrm{cm}$, slice thickness $=5-6 \mathrm{~mm}$, gap $=1-2 \mathrm{~mm}, \mathrm{NEX}=2$ (breath hold; 4-5 for free breathing), TE/TR $=1.4 / 2.8$ (Siemens), $\mathrm{TE} / \mathrm{TR}=2.0 / 4.0(\mathrm{GE})$, in-plane resolution $=$ 1.2- $2.2 \mathrm{~mm}$. A minimum of 12 slices were performed, with 20 phases/slice. The typical temporal resolution of the cine SSFP images was $30-40 \mathrm{~ms}$; they and were adjusted according to the patient heart rate and ability to breath-hold. The RF flip angles were set between $50^{\circ}-70^{\circ}$ dependent on the patient weight, height and the SAR level.

Tagged cine CMR images were acquired in the short axis of the midventricle at the level of the papillary muscles using an ECG-triggered segmented k-space fast gradient echo sequence with spatial modulation of magnetization in orthogonal planes. Tag imaging was performed prior to administration of Gadolinium. Grid tag spacing was 7-8 $\mathrm{mm}$. The scan parameters used were: field of view $=(30-32) \times(25-26) \mathrm{cm}^{2}$, slice thickness $=$ $6 \mathrm{~mm}$, flip $=20^{\circ}, \mathrm{TE} / \mathrm{TR}=3 \mathrm{~ms} / 6.6 \mathrm{~ms}(\mathrm{GE}),=3 \mathrm{~ms} / 4.2$ $\mathrm{ms}$ (Siemens), views per segment $=8(\mathrm{GE}),=7-9(\mathrm{Sie}-$ mens). Tagged images were analyzed using the HARmonic Phase (HARP, Diagnosoft, CA, USA) technique [23,28-32]. Only the mid-ventricular slice was analyzed, based on our experience and others' [23] of limited reproducibility of the basal and apical slices. Details of the $\varepsilon_{\mathrm{cc}}$ analysis have been previously described by Hor et al. [24]. The $\varepsilon_{\mathrm{cc}}$ data was exported to a spreadsheet file for analysis.

Cardiac functional imaging was performed to determine LV volumes, mass and EF using semi-automated endocardial and epicardial segmentation (QMASS v.6.1.5, Medis Medical Imaging Systems) Netherlands and circumferential strain $\left(\boldsymbol{\varepsilon}_{\mathrm{cc}}\right)$ using HARmonic Phase analysis (HARP, Diagnosoft, Palo Alto, California) as previously described [23-25,29-31,33-35].

Results are expressed as mean \pm SD for continuous data and as percentages and numbers for categorical data. Continuous variables were compared using twosample t-test and categorical variables were compared using Fisher exact-test. Analysis of covariance (ANCOVA) was used to assess the effect of medications on several clinical measurements with age as a continuous covariate in the model. All tests were 2-sided, and a p-value $<0.05$ was considered statistically significant. SAS version 9.2 (SAS Institute Inc., Cary, NC) was used for all analyses. 


\section{Results}

We identified 171 DMD patients $>5$ years of age that had undergone CMR examination. A total of 256 studies were available for review as a number of patients had multiple studies. We excluded 50 studies for either no corticosteroid treatment at the time of study (36 studies) or treatment with beta-blockers at the time of study (14 studies). The remaining 206 studies from 136 patients were divided into two groups: Group A (corticosteroids alone, $\mathrm{n}=114$ ) and Group B (corticosteroids plus ACEI or ARB, $n=92$ ). Group A patients were significantly ( $<<$ $0.0001)$ younger $(10 \pm 2.4$ years) than Group B patients (12.4 \pm 3.2 years).

The average steroid dose was similar between Group A and Group B $(0.7 \pm 0.29 \mathrm{mg} / \mathrm{kg} /$ day, range $0.1-1.9$ vs. $0.6 \pm$ $0.22 \mathrm{mg} / \mathrm{kg} /$ day, range $0.1-1.3, \mathrm{p}=0.48)$. The patients in Group B were on standard dose of ACEI $(0.16 \pm 0.29 \mathrm{mg} /$ $\mathrm{kg} /$ day, range $0.04-1.23)$ and ARB $(0.73 \pm 0.29 \mathrm{mg} / \mathrm{kg} /$ day, range $0.34-1.23$ ) (Table 1).

Heart rate, LV EF, LV end diastolic volume (LVEDV) and LV mass (LVM) were not different between the two groups. LVEF averaged across all patients in this cohort was normal, but $\boldsymbol{\varepsilon}_{\mathrm{cc}}$ magnitude was significantly lower in Group B (-12.8 \pm 2$)$ versus Group A patients $(-13.8 \pm 1.9$, $\mathrm{p}=0.0004)$. To determine the extent to which differences in the two groups was an effect of patient age, we performed a covariance analysis and treated age as a continuous variable (Table 2). The covariance model confirmed the lack of significant differences between Groups A and B with respect to heart rate, EF, LVEDV, LVM, LVRI or $\boldsymbol{\varepsilon}_{\mathrm{cc}}$ after controlling for age, implying lack of difference between the two groups other than the use of cardiac medications in Group B.

Additionally, to assess serial changes in EF and $\varepsilon_{\mathrm{cc}}$ we identified patients in Group A $(\mathrm{n}=28)$ and B $(\mathrm{n}=31)$ who underwent 2 CMR studies during the observation period. This included 11 patients who crossed from Group A to B between sequential studies. Among individuals with 2 studies, EF and $\boldsymbol{\varepsilon}_{\mathrm{cc}}$ values were compared between the two studies (Figure 1). EF changes between the first and second study were variable across three groups, while the majority of patients had decline in $\boldsymbol{\varepsilon}_{\mathrm{cc}}$ magnitude over the same study period. In Group A, $50 \%(14 / 28)$ patients had decrease EF while the other $50 \%(14 / 28)$ had increase EF. Of Group A patients, 7\% $(2 / 28)$ had changes in EF by $>10 \%$, however one increased by almost $15 \%$ and the other decrease by $12 \%$. Both patient s continue to have normal EF ( $>55 \%)$ on both studies. One patient had EF $<55 \%$ on the first study which remained the same on the second study and another patient had EF that decline from $59 \%$ to $54 \%$. However, only $14 \%(4 / 28)$ of Group A subjects had an increase $\boldsymbol{\varepsilon}_{\mathrm{cc}}$ magnitude while $86 \%(24 / 28)$ had worsening of $\boldsymbol{\varepsilon}_{\mathrm{cc}}$ magnitude. The findings for Group B were similar, with $68 \%(21 / 31)$ of patients having decrease EF and $32 \%(10 / 31)$ of patients with increase EF over the two study. Of Group B patients, 28\% (9/32) had changes in EF by $>10 \%$ with 6 patients having decrease EF and 3 patients with increase EF on the follow-up study. Of these, One patient started with an EF of $53 \%$ and increased to $64 \%$ on the follow-up study. Of the 6 patients with decrease in EF, three had $\mathrm{EF}<55 \%$ while the other three continue to have normal EF on the follow-up study. As in Group A, 84\% (26/31) of the Group B patients had decrease $\varepsilon_{\mathrm{cc}}$, while only $16 \%(5 / 31)$ subjects showed improvement in $\boldsymbol{\varepsilon}_{\mathrm{cc}}$ magnitude. For the patients that crossed from Group A to B, the percent of patients with improved EF was $45 \%$ (5/11) while $55 \%$ $(6 / 11)$ had decline in EF. The percent of patients with an increase in $\boldsymbol{\varepsilon}_{\mathrm{cc}}$ magnitude was $18 \%(2 / 11)$ but $82 \%$ (9/11) had worsening of $\boldsymbol{\varepsilon}_{\mathrm{cc}}$ magnitude (Figure 1). The average time between studies was the same across Group A, Group B and patients who transitioned from Group A to B. LVEF did not change significantly between baseline and follow-up in all three groups (Table 3). While $\varepsilon_{\mathrm{cc}}$ worsened from initial to follow-up CMR exam in all three groups, reduction in $\boldsymbol{\varepsilon}_{\mathrm{cc}}$ only reached statistical significance in Group B (Table 3).

Table 1 DMD Patients characteristics

\begin{tabular}{|c|c|c|c|}
\hline Parameter & Steroid Only $(A)(n=114)$ & Steroid plus ACEI_ARB (B)(n=92) & P-value \\
\hline Age (yrs) & $10.0 \pm 2.4$ & $12.4 \pm 3.2$ & $<0.0001$ \\
\hline Heart Rate (bpm) & $101 \pm 19$ & $104 \pm 15$ & 0.2498 \\
\hline LVEDV $(\mathrm{mL})$ & $82.5 \pm 21.8$ & $86.7 \pm 24.8$ & 0.2023 \\
\hline LVM (g) & $58.6 \pm 19.4$ & $62.1 \pm 19.8$ & 0.1031 \\
\hline $\mathrm{EF}(\%)$ & $64.2 \pm 6.1$ & $62.8 \pm 7.5$ & 0.1414 \\
\hline$\varepsilon_{\subset \subset}(\%)$ & $-13.8 \pm 1.9$ & $-12.8 \pm 2.0$ & 0.0004 \\
\hline Steroid dose (gram/kg/day) & $0.7 \pm 0.29$ & $0.6 \pm 0.22$ & 0.4838 \\
\hline ACE-I dose (gram/kg/day) & N/A & $0.16 \pm 0.08$ & N/A \\
\hline ARB dose (gram/kg/day) & $\mathrm{N} / \mathrm{A}$ & $0.73 \pm 0.29$ & N/A \\
\hline
\end{tabular}

Abbreviations: ACE-I = Angiontension Converting Enzyme Inhibitor, ARB = Angiotension Receptor Blocker, bpm = beat per minute, Clinic Prior to CMR = Previous Clinic Visit Documenting Medication and Dose Prior to Cardiac Magnetic Resonance Imaging Study, DMD = Duchenne Muscular Dystrophy, $\varepsilon_{c c}=$ Circumferential Strain, EF = Ejection Fraction, LVEDV = Left Ventricular Endiastolic Volume, LVM = Left Ventricular Mass. 
Table 2 Analysis of covariance summary results: Comparisons between steroid only vs. steroid plus ACEI_ARB (medication) adjusted for age as a continuous variable

\begin{tabular}{ccccc}
\hline Response Variable & \multicolumn{2}{c}{ Medication } & \multicolumn{2}{c}{ Age } \\
\cline { 2 - 5 } & F-statistics & P-value & F-statistics & P-value \\
\hline Heart Rate $(\mathrm{bpm})$ & 1.11 & 0.2930 & 0.00 & 0.9979 \\
LVEDV (mL) & 1.33 & 0.2503 & 37.01 & $<0.0001$ \\
LVM (g) & 2.19 & 0.1405 & 64.38 & $<0.0001$ \\
EF (\%) & 0.03 & 0.8594 & 9.10 & 0.0029 \\
$\varepsilon_{c \mathrm{cc}}(\%)$ & 1.74 & 0.1885 & 30.85 & $<0.0001$ \\
\hline
\end{tabular}

Abbreviations: $\mathrm{ACE}-\mathrm{I}=$ Angiontension Converting Enzyme Inhibitor, $\mathrm{ARB}=$ Angiotension Receptor Blocker, bpm $=$ beat per minute, $? \varepsilon_{\mathrm{cc}}=$ Circumferential Strain, EF = Ejection Fraction, LVEDV = Left Ventricular Endiastolic Volume, LVM $=$ Left Ventricular Mass.

\section{Discussion}

This study represents the largest cohort of DMD patients analyzed for the effect of medical therapy on the natural history of DMD-associated cardiac disease. Albeit retrospective, these results suggest that treatment with either an ACEI or ARB does not arrest the decline in DMD-associated cardiac function in patients receiving corticosteroids. In fact, we found a statistically significant worsening in $\boldsymbol{\varepsilon}_{\mathrm{cc}}$ in patients taking both corticosteroids and ACEI or ARB, suggesting that current approaches are inadequate in arresting decline in cardiac function.

Clinical assessment of DMD-associated cardiac disease is particularly challenging, as overt decompensation typically occurs only in the terminal stages of disease at a time when clinical assessment of cardiac function is limited. A sensitive and specific parameter such as $\boldsymbol{\varepsilon}_{\mathrm{cc}}$ could thus assume great importance in management of these patients. Previous studies have shown that changes in $\boldsymbol{\varepsilon}_{\mathrm{cc}}$ precede decline in LVEF in DMD-associated cardiac disease as well as in both hypertrophic and hypertensive cardiomyopathy [24,36-38]. Using such an early marker of subclinical disease in a cohort with preserved LVEF, we were unable to detect an improvement with standard therapies.

Assessment of cardiac effects of corticosteroid therapy in animal models and patients has historically yielded mixed results. For example, corticosteroids have been shown to improve systolic function in children with myocarditis but

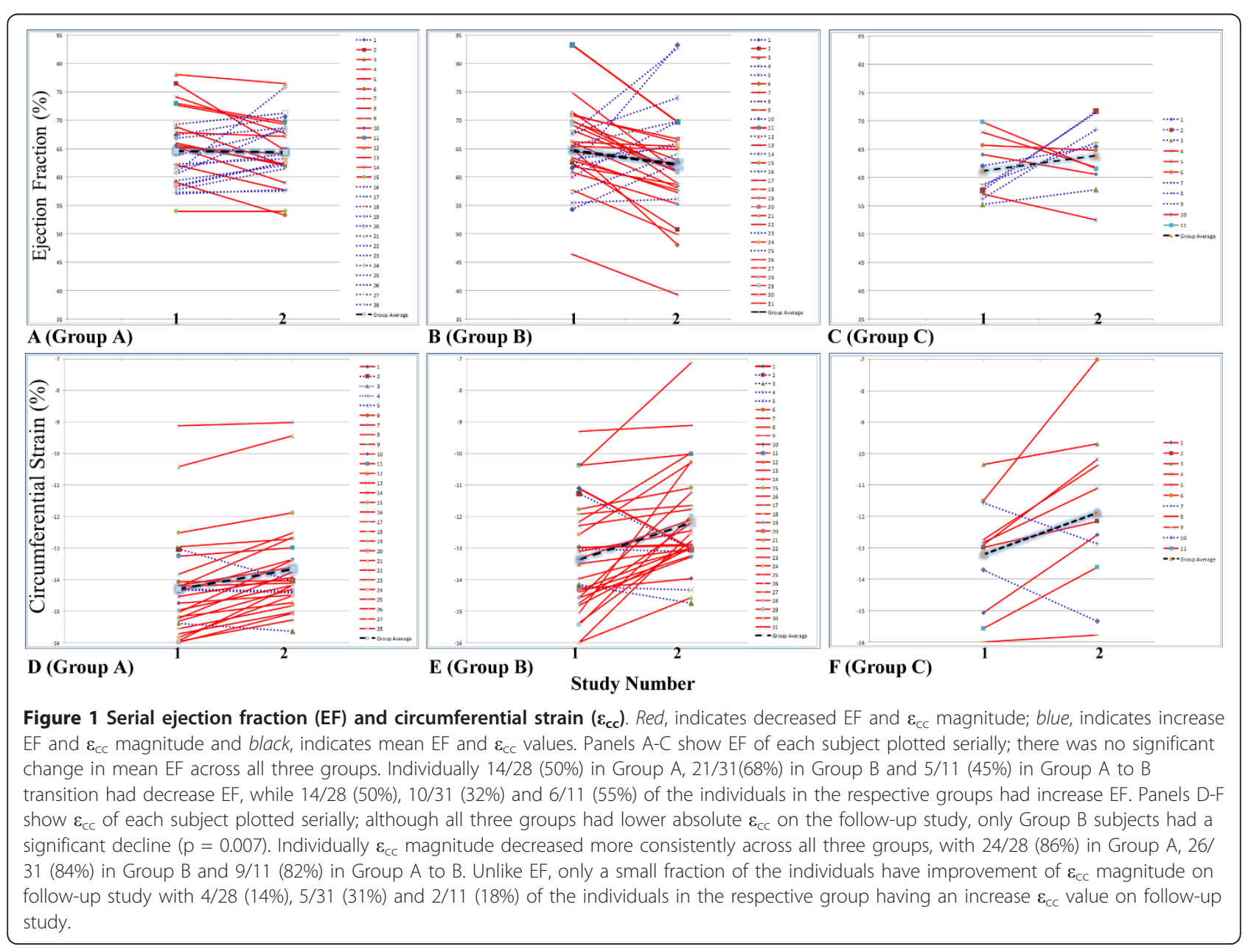


Table 3 Results from Serial CMR Exams Across DMD Treatment Groups

\begin{tabular}{|c|c|c|c|c|c|c|c|c|c|}
\hline \multirow{2}{*}{$\begin{array}{l}\text { Group/Patients Time Interval (months) } \\
\text { CMR Study }\end{array}$} & \multicolumn{3}{|c|}{$\begin{array}{l}\text { Group A (Steroids); } \mathrm{n}=28 \\
\text { Mean = } 14.9 \pm 5.6 \\
\text { Range = 8.5-29.7 }\end{array}$} & \multicolumn{3}{|c|}{$\begin{array}{l}\text { Group B (Steroids plus ACEI/ARB); } n=31 \\
\text { Mean }=15.1 \pm 5.9 \text { Range }=8.4-35.8\end{array}$} & \multicolumn{3}{|c|}{$\begin{array}{l}\text { Group } A \text { to } B ; n=11 \\
\text { Mean }=15.6 \pm 5.9 \text { Range }=5.8-25.5\end{array}$} \\
\hline & Study 1 & Study 2 & P-value & Study 1 & Study 2 & P-value & Study 1 & Study 2 & P-value \\
\hline Age (yrs) & $9.30 \pm 1.5$ & $10.5 \pm 1.6$ & $<0.005$ & $11.7 \pm 3.4$ & $12.97 \pm 3.4$ & 0.148 & $10.8 \pm 2.5$ & $12.0 \pm 2.2$ & 0.252 \\
\hline $\mathrm{HR}$ (bpm) & $101 \pm 21$ & $99 \pm 16$ & 0.762 & $105 \pm 14$ & $105 \pm 15$ & 0.996 & $100 \pm 14$ & $102 \pm 18$ & 0.682 \\
\hline LVEDV (mL) & $82.7 \pm 19.3$ & $86.5 \pm 21.6$ & 0.494 & $84.9 \pm 29.2$ & $90.0 \pm 30.8$ & 0.499 & $85.6 \pm 18.6$ & $81.2 \pm 15.6$ & 0.556 \\
\hline LVM (g) & $57.1 \pm 15.1$ & $57.7 \pm 16.9$ & 0.890 & $60.9 \pm 21.4$ & $65.0 \pm 21.4$ & 0.478 & $61.3 \pm 31.2$ & $60.1 \pm 14.0$ & 0.909 \\
\hline EF (\%) & $64.6 \pm 6.3$ & $64.4 \pm 5.8$ & 0.906 & $64.9 \pm 6.7$ & $62.2 \pm 9.1$ & 0.194 & $61.2 \pm 5.0$ & $63.8 \pm 5.8$ & 0.261 \\
\hline$\varepsilon_{\subset c}(\%)$ & $-14.3 \pm 1.6$ & $-13.7 \pm 1.5$ & 0.135 & $-13.4 \pm 1.7$ & $-12.1 \pm 1.6$ & 0.007 & $-13.2 \pm 1.8$ & $-11.9 \pm 2.7$ & 0.179 \\
\hline
\end{tabular}

Abbreviations: $\mathrm{BMP}=$ beat per minute, $\mathrm{DMD}=$ Duchenne Muscular Dystrophy, $\varepsilon_{\mathrm{cc}}=$ Circumferential Strain, $\mathrm{EF}=$ Ejection Fraction, $\mathrm{ACEl}=$ angiotensin converting enzyme inhibitor, $\mathrm{ARB}=$ angiotensin receptor blocker $\mathrm{HR}=$ heart rate, LVEDV = Left Ventricular Endiastolic Volume (milliliter), LVM = Left Ventricular Mass (gram). 
not with dilated cardiomyopathy [39]. Markham et al demonstrated that freedom from ventricular dysfunction at approximately 50 months between retrospectivelyreviewed echocardiograms was $93 \%$ for steroid treated versus 53\% for untreated DMD cases [6]. However, in a mouse model of dystrophin deficiency, Bauer et al demonstrated acceleration of cardiac dysfunction in steroid treated animals [40]. Recently, Pereira et al [41] observed normalization of multidirectional (radial, longitudinal and circumferential) strain assessed by $2 \mathrm{D}$ echo speckle tracking in Cushing syndrome patients following normalization of corticosteroid excess; they concluded that corticosteroid excess not only induced LV hypertrophy and diastolic dysfunction but also subclinical systolic dysfunction, which reverses upon normalization of corticosteroid excess. While there is universal agreement that steroids prolong ambulation in the DMD patient population (reviewed in [21]), the current study failed to identify a cardioprotective effect of steroids.

Several studies have suggested beneficial effects of ACEI on LV function in small cohorts [17-19,42]. In a murine DMD model, Bauer et al showed hemodynamic benefit to dystrophin-deficient mice treated with ACEI alone [40]. Jefferies et al suggested that this effect may be linked to specific mutations [19] in humans, but Ramaciotti et al [42] did not confirm this finding. In addition to $\varepsilon_{\mathrm{cc}}$, we found no difference in EF between baseline and 15 months, which is at odds with the findings of Duboc et al [17] who found that treatment with perindopril delayed the onset and progression of LV dysfunction in children. There are several possible explanations for the differences in findings. First, in our cohort, the time between the serial CMR studies might be insufficient to develop detectable LV EF decline. However, one would expect to detect more subclinical changes using the more sensitive measure LV $\boldsymbol{\varepsilon}_{\mathrm{cc}}$. Furthermore, without an untreated control group, the fact that $\boldsymbol{\varepsilon}_{\mathrm{cc}}$ magnitude declined only slightly may represent a "good" outcome, as LV function of untreated patients may decline more precipitously. Despite smaller studies reporting benefit of $\mathrm{ACEI}$ and $\mathrm{BB}$, there is no published data demonstrating longer life expectancy in DMD boys undergoing "adultlike" CHF therapy.

A long-standing hypothesis regarding DMD-associated cardiac disease pathogenesis is that loss of membrane integrity is a primary event leading to myocyte degeneration. Intermittent tears in the cell membrane permit influx of calcium that then functions as a primary inducer of a destructive cascade culminating in myocyte necrosis and replacement fibrosis [43]. Although there has been intense interest in treating DMD-associated cardiac disease, successful therapies remain elusive [22,44-46]. Findings in the current study underscore the need for randomized studies in DMD population. As in cases of heart failure in adult population, development of heart failure with normal EF starts early (HFNEF) and proceeds to systolic dysfunction. Of interest, studies in adult HFNEF patients treated with ACEI or BB have not demonstrated improvement in mortality compared to placebo [47-49]. In boys with DMD, dystrophin mutation dictates eventual LV dysfunction and once systolic dysfunction and myocardial fibrosis develop, clinical disease typically progresses very rapidly and longterm survival (as seen in adult patients with LV systolic dysfunction) is poor. As such, the window of opportunity to treat DMD-associated cardiac disease needs to be advanced to when $\boldsymbol{\varepsilon}_{\mathrm{cc}}$ is abnormal but EF has not yet begun its inexorable declined.

\section{Study Limitations}

Study design based on physician preference is a major limitation of the study and includes retrospective, mostly cross-sectional data with no control group and with strong confounding of group allocation by age of boys being prescribed therapy. Older boys tended to be on combination treatment while younger boys were often treated with steroids alone. Further, longitudinal data is limited. Other confounding factors are very difficult to control for but are beyond the scope of this manuscript. As such, no firm conclusions can be drawn regarding the response rates to steroid or ACEI/ARB use. Further, findings are limited to patients $>5$ years since in our experience patients $<5$ years of age cannot undergo CMR without sedation. While it is possible, that 15 months follow-up was too short to detect therapeutic benefits, studies in other populations with preserved EF but measurable diastolic dysfunction have shown improvement in circumferential and longitudinal strain 12 months after ARB initiation [50].

\section{Conclusions}

These results support the need for rigorous, prospective clinical trials to identify more effective treatment regimens for DMD-associated cardiac disease.

\section{List of Abbreviations}

ACEl: Angiotensin Converting Enzyme Inhibitor; ARB: Angiotension Receptor Blocker; BB: Beta blockers; bpm: beat per minute; Clinic Prior to CMR: Previous Clinic Visit Documenting Medication and Dose Prior to CMR; CMR: Cardiovascular Magnetic Resonance; DMD: Duchenne Muscular Dystrophy; $\varepsilon_{c c}$ : Circumferential Strain; EF: Ejection Fraction; Group A: Steroid only; Group B: Steroid plus; HR: heart rate; LV: Left Ventricular; LVEDV: Left Ventricular Endiastolic Volume; LVM: Left Ventricular Mass; MO: months.

\section{Acknowledgements and Funding}

This work is dedicated to the memory of William M. Gottliebson, MD. Supported in part by the Children's Heart Association of Cincinnati (WMG) and the National Institutes of Health HL069712 (DWB) Bethesda, MD.

\section{Author details}

'The Heart Institute, Cincinnati Children's Hospital Medical Center, Cincinnati, Ohio, USA. ${ }^{2}$ The Heart and Vascular Center at The Christ Hospitals, Cincinnati, 
Ohio, USA. ${ }^{3}$ Duke University School of Medicine, Durham, North Carolina, USA. ${ }^{4}$ The Ohio State University, Columbus, Ohio, USA.

\section{Authors' contributions}

$\mathrm{KNH}$ and DWB contributed to all aspects of the manuscript's conception, design, data analysis, collection, critical revision and final approval. HRA, contributed to statistical analysis, revision and final approval. MDT, LHC, JLJ, SVR, ESC, KJH, KW and WMG* contributed in interpretation of the data, critical revision and final approval of the manuscript. All authors have read and approved the final manuscript

*WMG passed on September 17, 2010 and therefore, did not have the opportunity to give final approval of the manuscript but contributed significantly to it.

\section{Competing interests}

The authors declare that they have no competing interests.

Received: 18 March 2011 Accepted: 19 October 2011

Published: 19 October 2011

\section{References}

1. Hoffman EP, Brown RH, Kunkel LM: Dystrophin: the protein product of the Duchene muscular dystrophy locus. 1987. Biotechnology 1992, 24:457-466.

2. Kunkel LM, Monaco AP, Middlesworth W, Ochs HD, Latt SA: Specific cloning of DNA fragments absent from the DNA of a male patient with an X chromosome deletion. Proc Natl Acad Sci USA 1985, 82:4778-4782.

3. Ray PN, Belfall B, Duff C, Logan C, Kean V, Thompson MW, Sylvester JE, Gorski JL, Schmickel RD, Worton RG: Cloning of the breakpoint of an X;21 translocation associated with Duchenne muscular dystrophy. Nature 1985, 318:672-675.

4. Bushby K, Muntoni F, Urtizberea A, Hughes R, Griggs R: Report on the 124th ENMC International Workshop. Treatment of Duchenne muscular dystrophy; defining the gold standards of management in the use of corticosteroids. 2-4 April 2004, Naarden, The Netherlands. Neuromuscul Disord 2004, 14:526-534.

5. Finder JD, Birnkrant D, Carl J, Farber HJ, Gozal D, lannaccone ST, Kovesi T, Kravitz RM, Panitch H, Schramm C, et al: Respiratory care of the patient with Duchenne muscular dystrophy: ATS consensus statement. Am J Respir Crit Care Med 2004, 170:456-465.

6. Markham LW, Spicer RL, Khoury PR, Wong BL, Mathews KD, Cripe LH: Steroid therapy and cardiac function in Duchenne muscular dystrophy. Pediatr Cardiol 2005, 26:768-771.

7. Angermann C, Spes C, Pongratz D: [Cardiac manifestation of progressive muscular dystrophy of the Duchenne type]. Z Kardiol 1986, 75:542-551.

8. de Kermadec JM, Becane HM, Chenard A, Tertrain F, Weiss Y: Prevalence of left ventricular systolic dysfunction in Duchenne muscular dystrophy: an echocardiographic study. Am Heart J 1994, 127:618-623.

9. Markham LW, Michelfelder EC, Border WL, Khoury PR, Spicer RL, Wong BL, Benson DW, Cripe LH: Abnormalities of diastolic function precede dilated cardiomyopathy associated with Duchenne muscular dystrophy. J Am Soc Echocardiogr 2006, 19:865-871.

10. Markham LW, Spicer RL, Cripe LH: The heart in muscular dystrophy. Pediatr Ann 2005, 34:531-535.

11. Wong BL, Mukkada VA, Markham LW, Cripe LH: Depressed left ventricular contractile reserve diagnosed by dobutamine stress echocardiography in a patient with Duchenne muscular dystrophy. J Child Neurol 2005, 20:246-248.

12. Fong PY, Turner PR, Denetclaw WF, Steinhardt RA: Increased activity of calcium leak channels in myotubes of Duchenne human and $\mathrm{mdx}$ mouse origin. Science 1990, 250:673-676.

13. Moriuchi T, Kagawa N, Mukoyama M, Hizawa K: Autopsy analyses of the muscular dystrophies. Tokushima J Exp Med 1993, 40:83-93.

14. Puchalski MD, Williams RV, Askovich B, Sower CT, Hor KH, Su JT, Pack N, Dibella $\mathrm{E}$, Gottliebson WM: Late gadolinium enhancement: precursor to cardiomyopathy in Duchenne muscular dystrophy? Int J Cardiovasc Imaging 2009, 25:57-63.

15. Silva MC, Meira ZM, Gurgel Giannetti J, da Silva MM, Campos AF, Barbosa Mde M, Starling Filho GM, Ferreira Rde A, Zatz M, Rochitte CE: Myocardial delayed enhancement by magnetic resonance imaging in patients with muscular dystrophy. J Am Coll Cardiol 2007, 49:1874-1879.
16. Markham LW, Kinnett K, Wong BL, Woodrow Benson D, Cripe LH: Corticosteroid treatment retards development of ventricular dysfunction in Duchenne muscular dystrophy. Neuromuscul Disord 2008, 18:365-370.

17. Duboc D, Meune C, Lerebours G, Devaux JY, Vaksmann G, Becane HM: Effect of perindopril on the onset and progression of left ventricular dysfunction in Duchenne muscular dystrophy. J Am Coll Cardiol 2005, 45:855-857.

18. Duboc D, Meune C, Pierre B, Wahbi K, Eymard B, Toutain A, Berard C, Vaksmann G, Weber S, Becane HM: Perindopril preventive treatment on mortality in Duchenne muscular dystrophy: 10 years' follow-up. Am Heart J 2007, 154:596-602.

19. Jefferies $J$, Eidem BW, Belmont JW, Craigen WJ, Ware SM, Fernbach SD, Neish SR, Smith EO, Towbin JA: Genetic predictors and remodeling of dilated cardiomyopathy in muscular dystrophy. Circulation 2005, 112:2799-2804.

20. Bushby K, Finkel R, Birnkrant DJ, Case LE, Clemens PR, Cripe L, Kaul A Kinnett K, McDonald C, Pandya S, et al: Diagnosis and management of Duchenne muscular dystrophy, part 2: implementation of multidisciplinary care. Lancet Neurol 2010, 9:177-189.

21. Bushby K, Finkel R, Birnkrant DJ, Case LE, Clemens PR, Cripe L, Kaul A, Kinnett K, McDonald C, Pandya S, et al: Diagnosis and management of Duchenne muscular dystrophy, part 1: diagnosis, and pharmacological and psychosocial management. Lancet Neurol 2010, 9:77-93.

22. Cripe LH, Barber BJ, Spicer RL, Wong BL, Weidner N, Benson DW, Markham LW: Outpatient continuous inotrope infusion as an adjunct to heart failure therapy in Duchenne muscular dystrophy. Neuromuscul Disord 2006, 16:745-748.

23. Ashford MW Jr, Liu W, Lin SJ, Abraszewski P, Caruthers SD, Connolly AM, Yu X, Wickline SA: Occult cardiac contractile dysfunction in dystrophindeficient children revealed by cardiac magnetic resonance strain imaging. Circulation 2005, 112:2462-2467.

24. Hor KN, Wansapura J, Markham LW, Mazur W, Cripe LH, Fleck R, Benson DW, Gottliebson WM: Circumferential strain analysis identifies strata of cardiomyopathy in Duchenne muscular dystrophy: a cardiac magnetic resonance tagging study. J Am Coll Cardiol 2009, 53:1204-1210.

25. Hagenbuch SC, Gottliebson WM, Wansapura J, Mazur W, Fleck R, Benson DW, Hor KN: Detection of progressive cardiac dysfunction by serial evaluation of circumferential strain in patients with Duchenne muscular dystrophy. Am J Cardiol 2010, 105:1451-1455.

26. Pennell DJ, Sechtem UP, Higgins CB, Manning WJ, Pohost GM, Rademakers FE, van Rossum AC, Shaw LJ, Yucel EK: Clinical indications for cardiovascular magnetic resonance (CMR): Consensus Panel report. Eur Heart J 2004, 25:1940-1965.

27. Pohost GM, Hung L, Doyle M: Clinical use of cardiovascular magnetic resonance. Circulation 2003, 108:647-653.

28. Gotte MJ, Germans T, Russel IK, Zwanenburg JJ, Marcus JT, van Rossum AC, van Veldhuisen DJ: Myocardial strain and torsion quantified by cardiovascular magnetic resonance tissue tagging: studies in normal and impaired left ventricular function. J Am Coll Cardiol 2006, 48:2002-2011.

29. Osman NF, Kerwin WS, MCVeigh ER, Prince $\mathrm{J}$ : Cardiac motion tracking using CINE harmonic phase (HARP) magnetic resonance imaging. Magn Reson Med 1999, 42:1048-1060.

30. Osman NF, McVeigh ER, Prince JL: Imaging heart motion using harmonic phase MRI. IEEE Trans Med Imaging 2000, 19:186-202.

31. Osman NF, Prince $J$ : Regenerating MR tagged images using harmonic phase (HARP) methods. IEEE Trans Biomed Eng 2004, 51:1428-1433.

32. Garot J, Bluemke DA, Osman NF, Rochitte CE, McVeigh ER, Zerhouni EA, Prince $J L$, Lima JA: Fast determination of regional myocardial strain fields from tagged cardiac images using harmonic phase MRI. Circulation 2000, 101:981-988.

33. van der Geest RJ, Reiber JH: Quantification in cardiac MRI. J Magn Reson Imaging 1999, 10:602-608.

34. Osman NF, Sampath S, Atalar E, Prince JL: Imaging longitudinal cardiac strain on short-axis images using strain-encoded MRI. Magn Reson Med 2001, 46:324-334.

35. Osman NF, Prince JL: Visualizing myocardial function using HARP MRI. Phys Med Biol 2000, 45:1665-1682.

36. Ennis DB, Epstein FH, Kellman P, Fananapazir L, McVeigh ER, Arai AE: Assessment of regional systolic and diastolic dysfunction in familial 
hypertrophic cardiomyopathy using MR tagging. Magn Reson Med 2003, 50:638-642.

37. Rosen BD, Saad MF, Shea S, Nasir K, Edvardsen T, Burke G, JeroschHerold M, Arnett DK, Lai S, Bluemke DA, Lima JA: Hypertension and smoking are associated with reduced regional left ventricular function in asymptomatic: individuals the Multi-Ethnic Study of Atherosclerosis. $J$ Am Coll Cardiol 2006, 47:1150-1158.

38. Young AA, Kramer CM, Ferrari VA, Axel L, Reichek N: Three-dimensional left ventricular deformation in hypertrophic cardiomyopathy. Circulation 1994, 90:854-867.

39. Gagliardi MG, Bevilacqua M, Bassano C, Leonardi B, Boldrini R, Camassei FD, Fierabracci A, Ugazio AG, Bottazzo GF: Long term follow up of children with myocarditis treated by immunosuppression and of children with dilated cardiomyopathy. Heart 2004, 90:1167-1171.

40. Bauer R, Straub V, Blain A, Bushby K, MacGowan GA: Contrasting effects of steroids and angiotensin-converting-enzyme inhibitors in a mouse model of dystrophin-deficient cardiomyopathy. Eur J Heart Fail 2009, 11:463-471.

41. Pereira AM, Delgado V, Romijn JA, Smit JW, Bax JJ, Feelders RA: Cardiac dysfunction is reversed upon successful treatment of Cushing's syndrome. Eur J Endocrinol 2010, 162:331-340.

42. Ramaciotti C, Heistein LC, Coursey M, Lemler MS, Eapen RS, lannaccone ST, Scott WA: Left ventricular function and response to enalapril in patients with duchenne muscular dystrophy during the second decade of life. Am J Cardiol 2006, 98:825-827.

43. Millay DP, Goonasekera SA, Sargent MA, Maillet M, Aronow BJ, Molkentin JD: Calcium influx is sufficient to induce muscular dystrophy through a TRPC-dependent mechanism. Proc Natl Acad Sci USA 2009, 106:19023-19028.

44. Shaddy RE, Tani LY, Gidding SS, Pahl E, Orsmond GS, Gilbert EM, Lemes V: Beta-blocker treatment of dilated cardiomyopathy with congestive heart failure in children: a multi-institutional experience. J Heart Lung Transplant 1999, 18:269-274.

45. Rhodes J, Margossian R, Darras BT, Colan SD, Jenkins KJ, Geva T, Powell AJ: Safety and efficacy of carvedilol therapy for patients with dilated cardiomyopathy secondary to muscular dystrophy. Pediatr Cardiol 2008, 29:343-351.

46. Shaddy RE, Boucek MM, Hsu DT, Boucek RJ, Canter CE, Mahony L, Ross RD, Pahl E, Blume ED, Dodd DA, et al: Carvedilol for children and adolescents with heart failure: a randomized controlled trial. JAMA 2007, 298:1171-1179.

47. Blanche C, Fumeaux T, Polikar R: Heart failure with normal ejection fraction (HFNEF): is it worth considering? Swiss Med Wkly 2010, 140:66-72.

48. Burkhoff $D$, Maurer MS, Packer M: Heart failure with a normal ejection fraction: is it really a disorder of diastolic function? Circulation 2003, 107:656-658

49. Hamdani N, Paulus WJ, van Heerebeek L, Borbely A, Boontje NM, Zuidwijk MJ, Bronzwaer JG, Simonides WS, Niessen HW, Stienen GJ, van der Velden J: Distinct myocardial effects of beta-blocker therapy in heart failure with normal and reduced left ventricular ejection fraction. Eur Heart J 2009, 30:1863-1872.

50. Mizuguchi Y, Oishi Y, Miyoshi H, luchi A, Nagase N, Oki T: Telmisartan improves morphologic and functional changes in both left ventricular myocardium and carotid arterial wall in patients with hypertension: assessment by tissue Doppler imaging and carotid ultrasonography. Echocardiography 2010, 27:864-872.

doi:10.1186/1532-429X-13-60

Cite this article as: Hor et al.: Effects of steroids and angiotensin converting enzyme inhibition on circumferential strain in boys with Duchenne muscular dystrophy: a cross-sectional and longitudinal study utilizing cardiovascular magnetic resonance. Journal of Cardiovascular Magnetic Resonance 2011 13:60

\section{Submit your next manuscript to BioMed Central and take full advantage of:}

- Convenient online submission

- Thorough peer review

- No space constraints or color figure charges

- Immediate publication on acceptance

- Inclusion in PubMed, CAS, Scopus and Google Scholar

- Research which is freely available for redistribution

Submit your manuscript at www.biomedcentral.com/submit
Ciomed Central 